\title{
RESULTS FROM A TETHERED ROCKET EXPERIMENT (CHARGE-2)
}

\author{
N. Kawashima," S. Sasaki," K. I. Oyama, "K. Hirao," T. Obayashi," \\ W. J. Raitt,"* A. B. White, ," P. R. Williamson, ${ }^{* * *}$ P. M. Banks"** \\ and W. F. Sharp $\dagger$ \\ "The Institute of Space and Astronautical Science, 6-1, Komaba 4-chome, \\ Meguro-ku, Tokyo 153, Japan \\ "Utah State University, Logan, UT 84322, U.S.A. \\ "."Stanford University, Stanford, CA 94305, U.S.A. \\ †University of Michigan, Ann Arbor, MI 48103, U.S.A.
}

\section{ABSTRACT}

A tethered payload experiment (Charge-2) was carried out as an international program between Japan and the USA using a NASA sounding rocket at White Sands Missile Range. The objective of the experiment was to perform a new type of active experiment in space by injecting an electron beam from a mother-daughter rocket system connected with a long tether wire. The electron beam with voltage and current up to $1 \mathrm{kV}$ and $80 \mathrm{~mA}$ (nominal) was injected from the mother payload. An insulated conductive wire of $426 \mathrm{~m}$ length connected the two payloads, the longest tether system flown so far. The electron gun system and diagnostic instruments (plasma, optical, particle and wave) functioned correctly throughout the flight. The potential rise of the mother payload during the electron beam emission was measured with respect to the daughter payload. The beam trajectory was detected by a camera onboard the mother rocket. Wave generation and current induction in the wire during the beam emission were also studied.

\section{INTRODUCTION}

Tether systems, i.e. dual spacecraft connected with a long wire, are considered as new and important tools for scientific exploration of space and practical application /1/ /2/. When the tether system is combined with an electron beam injection experiment it offers a number of possibilities for interesting scientific experiments and applications. One example is to study the spacecraft charging and charge neutralization. An efficient transmission of very low frequency radio waves is another example. It has also been proposed that the electron beam/tether system can be used to control the orbit of a spacecraft.

The present program's aims was to study the deployment of the tether system in a motherdaughter configuration and the interaction of the electron beam/tether system with the ionospheric plasma. It was carried out jointly by the Institute of Space and Astronautical Science (ISAS) and Utah State University (USU) in 1980 using a Japanese sounding rocket /3/ $14 / 15 /$. More recently, an experiment was conducted at White Sands in 1985 by using a NASA rocket. The experiment was a collaboration of ISAS, USU, Stanford University and University of Michigan.

\section{PAYLOAD INSTRUMENTS}

Figure 1 shows the configuration of the payload instruments. The mother payload was composed of an electron gun ( $1 \mathrm{keV} 80 \mathrm{~mA}$ (nominal) DC and pulsed (2, 8, 32, 256 $\mu \mathrm{s}$ and $65.5 \mathrm{~ms}$ ) operation), a floating/Langmuir probe array ( 4 electrodes mounted on a $1 \mathrm{~m}$ boom with $25 \mathrm{~cm}$ spacing), a thermal electron energy detector, two photometers with a filter at 3914 A to measure the optical emission from the beam and the wall sheath illumination, two $35 \mathrm{~mm}$ cameras to monitor the beam profile and the tether deployment, an electrostatic electron energy analyzer, a charge probe, a $500 \mathrm{~V}$ power supply to apply voltage beatween the mother and daughter payloads, a tether voltage/current monitor, a mechanical tension monitor, a tether wire cutting mechanism and a microprocessor to control these instruments and for data management. The daughter payload consisted of the Tether Deployment System (TDS), HF/VLF wave receivers, and a charge probe (DCP). TDS contained $426 \mathrm{~m}$ of wire and the deployment monitoring system with $0.1 \mathrm{~m}$ resolution. The wire was stainless steel, $0.66 \mathrm{~mm}$ in diameter, coated with teflon. A mechanism to cut the wire at re-entry was installed. Two sets of $2.4 \mathrm{~m}$-dipole antennas (tip-tip) were used for wave detection. The frequency spectrum of HF wave signals from $0.2 \mathrm{MHz}$ to $10 \mathrm{MHz}$ was analyzed every $250 \mathrm{~ms}$. VLF wave signals in a broad band from 0.4 to $30 \mathrm{kHz}$ were directly transmitted to ground via an Sband telemetry link. 


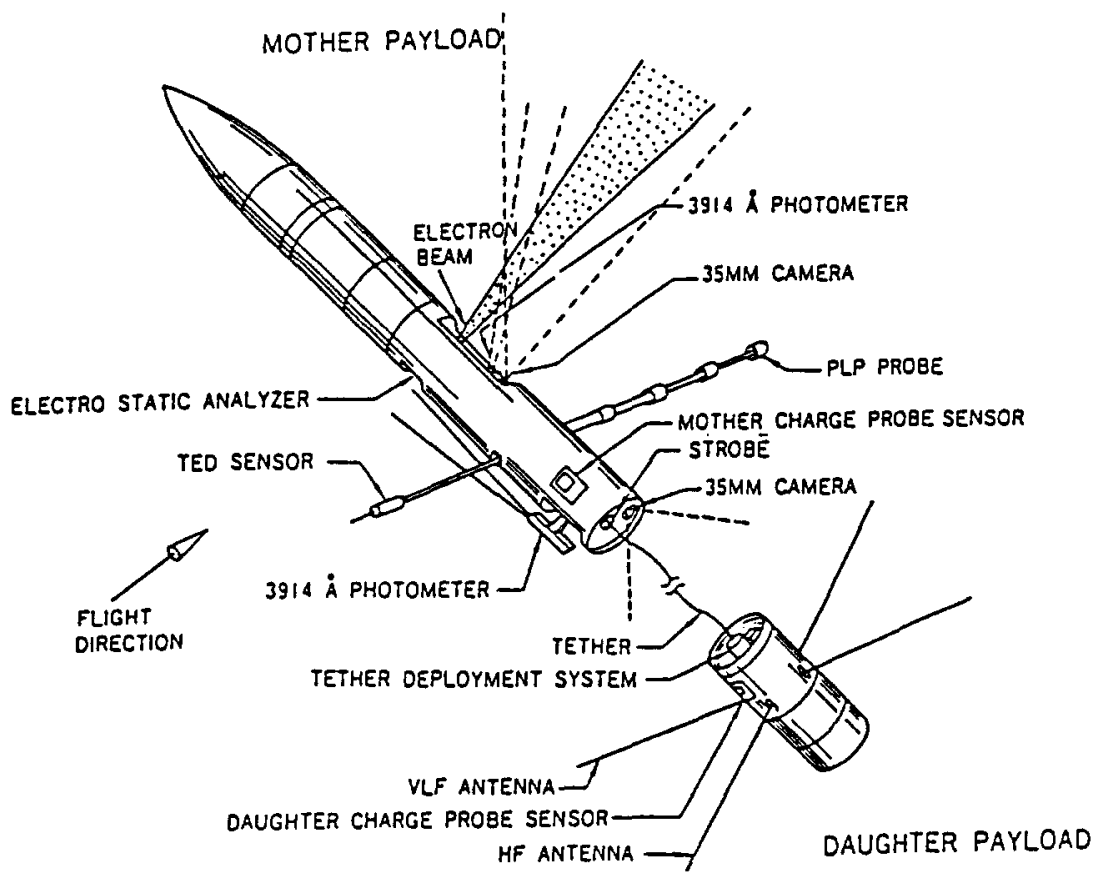

Fig. 1. Tether payload configuration.

\section{EXPERIMENT}

The Black Brant/Terrier rocket was launched at 00:16:42 (GMT 07:16:42) on 14 December 1985 at White Sands Missile Range, New Mexico. It reached an apogee of $262 \mathrm{~km}$ at $252 \mathrm{~s}$ after lift-off. The rocket was attitude controlled with its axis perpendicular to the geomagnetic field and with its nose directed towards west. The sequence of beam firings started at an altitude of $161 \mathrm{~km}$. The mother and daughter sections were separated by a multiple spring system at $193 \mathrm{~km}$ with an initial velocity of $1.05 \mathrm{~m} / \mathrm{s}$. The Reaction Control System (RCS) onboard the daughter payload was operated for $3 \mathrm{~s}$ every $36.5 \mathrm{~s}$ in order to maintain the separation velocity against the frictional force in the tether deployment system. The beam was injected with different pitch angles with respect to the geomagnetic field in steps of 45 degrees. A high voltage up to $500 \mathrm{~V}$ was occasionally applied between the two payloads through the conductive wire, with an without beam firings.

\section{EXPERIMENTAL RESULTS}

(a) Tether Wire Deployment. The mother-daughter sections were separated at $T=141.9 \mathrm{~s}$ $(193 \mathrm{~km})$. The initial separation velocity is estimated as $1.05 \mathrm{~m} / \mathrm{s}$. It was gradually accelerated by the RCS up to $2 \mathrm{~m} / \mathrm{s}$. The average velocity was $1.47 \mathrm{~m} / \mathrm{s}$. The photographs of the daughter payload (illuminated by a flash lamp) taken by the still camera onboard the mother payload show that the attitude of the two payloads was stable after separation. The daughter payload was observed until $53 \mathrm{~s}$ after separation (wire deployment up to $65 \mathrm{~m}$ ). The wire near the payload was continually observed during the deployment, and was found to be twisted. The total length of wire deployed during $290 \mathrm{~s}$ was $426 \mathrm{~m}$.

(b) Beam Profile. The beam profile was observed by a still camera in a configuration shown in Figure 1. ASA 3000 high sensitivity color film was used and the exposure time was 8 s. Figure 2 shows a picture of the beam profile with two layers of airglow $(6300 \mathrm{~A}$ and 3914 , in the upper part of the image) and scattered city lights. The beam profiles in other configurations relative to the geomagnetic field are shown in figure 3 . They agree well with theoretical predictions. For example, the bending of the beam is strongly dependent upon the pitch angle of the beam with respect to geomagnetic field. However, the luminosity diminishes as the beam traverses. This means that the background neutral gas density is not uniform and decreases as it departs from the rocket wall. The neutral gas density is governed by the outgassing. It is very interesting that the beam is brighter when it is emitted as a pulse.

(c) Mother/Daughter Potential. The potential diffearence between the two payloads was measured by the Mother Charge Probe onboard the mother payload. Since the rocket was launched almost vertically upwards and the daughter payload was separated towards East, it was biased positively during upleg and negatively during downleg. Figure 4 shows the $M / D$ 


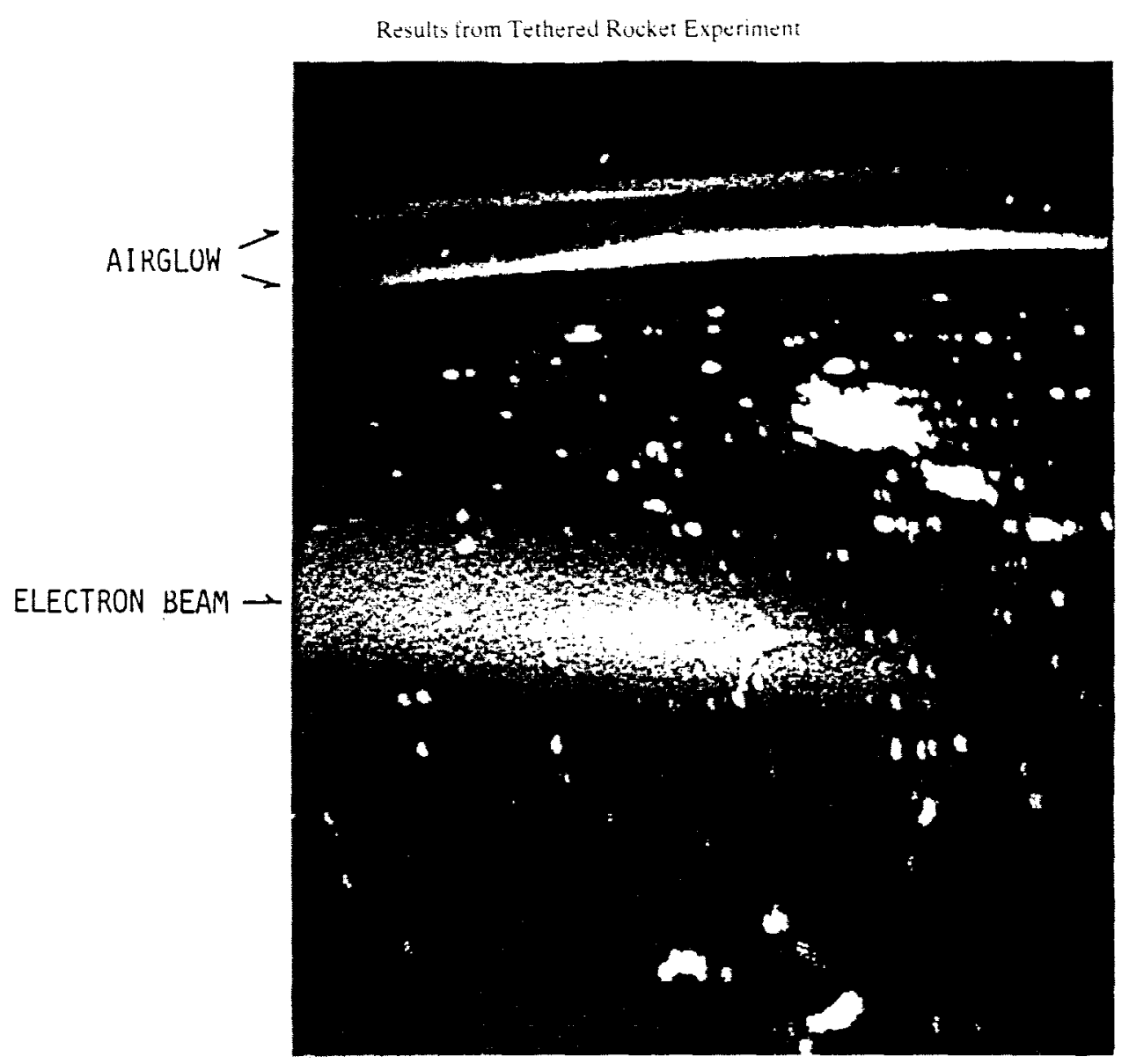

(1)199

Fig. 2. Electron beam profile on background of city lights and two layers of airglow (6300 A and $3914 \mathrm{~A}$, top of Figure).
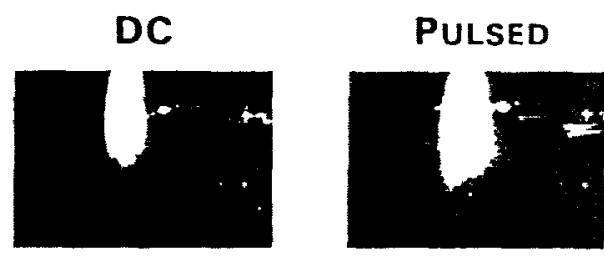

\author{
ALT 250KM \\ Pitch 12Deg.N
}
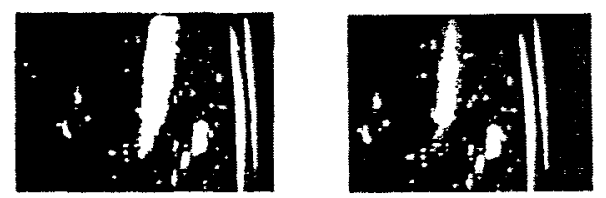

ALT 230KM
PITCH 57DEG.N
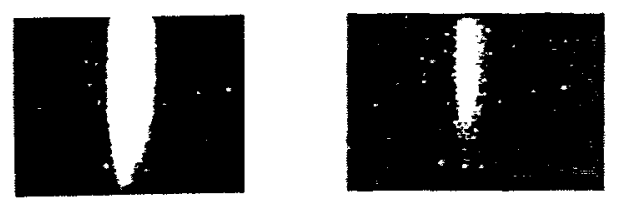

ALT $190 \mathrm{KM}$

Pitch 78deg.N
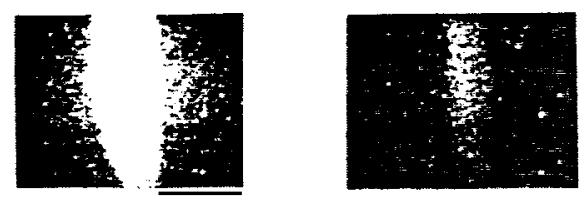

ALT $150 \mathrm{KM}$

PITCH 57DEg.S

Fig. 3. Beam profiles at other times. 
potential while the tether wire was deploying. The measurements in the first half agree with the model calculations in which the angle betwen the velocity vector and magnetic field ( 0.50 Gauss) was taken as 30.8 degrees. The cause of the large deviation in the latter half will be attributed to the high impedance between the surrounding plasma and the daughter payload, which was negatively biased during downleg.

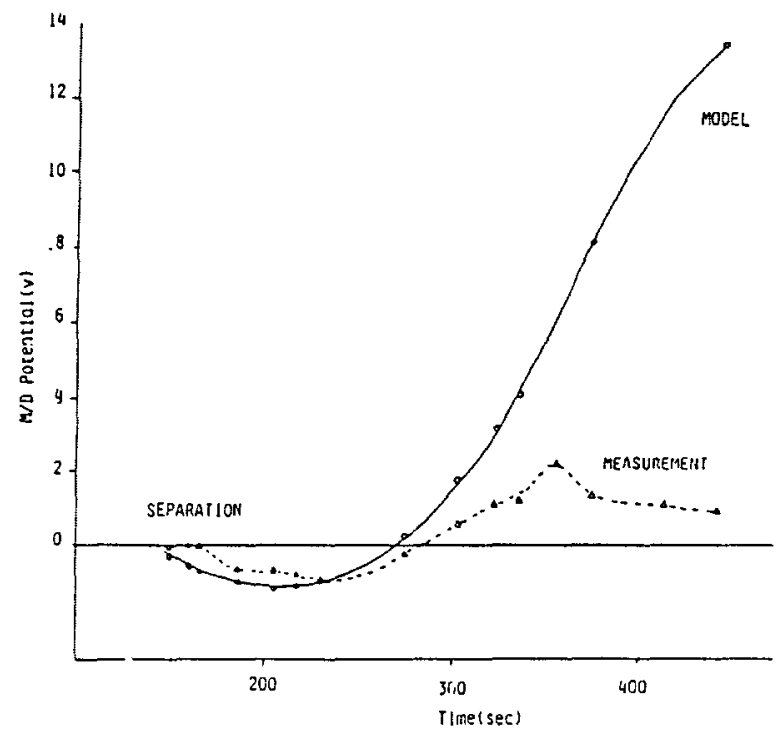

Fig. 4. Voltage between the mother and daughter payloads during tether deployment.

(d) Mother/Daughter Current. The current through the tether wire was detected during the beam emission. The current is approximately proportional to the beam current. The current increased by about $50 \%$ when $+500 \mathrm{~V}$ was applied to the daughter payload. When the background plasma density is higher, the tether current is also higher.

(e) Charging by Electron Beam Emission. The floating probe (-1100 V) and charge probe high gain data $(-9 \mathrm{~V})$ onboard the mother rocket have been used to analyze the rocket potential during the beam emission. The agreement between the two measurements is quite good although the dynamic range of the charge probe is limited. As is shown in Figure 5 , the charging was relatively low at higher altitudes when the beam current was small. This

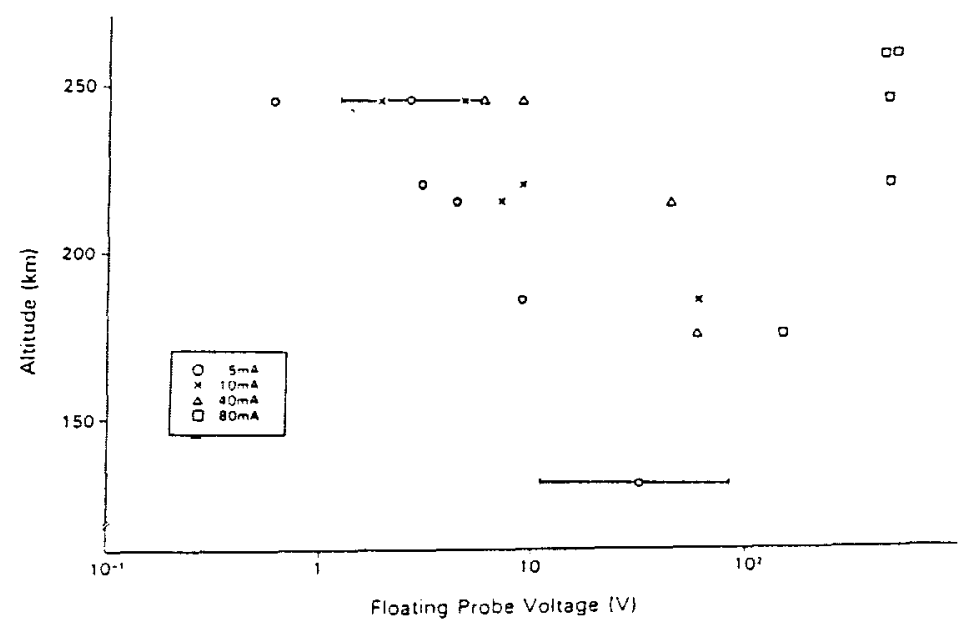

Fig. 5. Potential of mother payload as function of height and beam current. 
means that the electron beam emission is counterbalanced with the return current from the ionospheric plasma. By contrast, for a higher beam current the trend is opposite. The charge-up voltage was lower at lower altitudes, whereas at higher altitudes it was almost saturated, possibly indicating charging up to the bean acceleration voltage ( $-1000 \mathrm{~V})$. The difference between measured $(-500 \mathrm{~V})$ and beam accelerating voltage (1000 V) may be explained by the fact that the floating probes were immersed in the sheath. The reason why the charge-up voltage is lower at lower altitudes for higher beam current bay be some kind of non-linear beam plasma or beam neutral gas interaction.

No clear dependence on the pitch angle has been detected. For a beam emission of less than $80 \mathrm{~mA}$, the charging decreases with decreasing background plasma density. No remarkable difference of the charging was detected when the daughter and mother payloads were electrically connected or disconnected, or biased up to $500 \mathrm{~V}$ during the beam emission ( 80 $\mathrm{mA}$ ). This means that the electron current collected by the daughter payload was negligibly smaller than the $80 \mathrm{~mA}$ of the beam current.

(f) VLF Wave Measurements. The VLF AGC level (integrated wave intensity up to 30 kHz) measured at the daughter payload (background level without beam emission) increased on the average with the length of the tether wire. It dropped abruptly when the tether wire was cut at the daughter payload. This suggests that the tether wire acted as a VLF antenna.

Very strong waves were generated when the electron beam was emitted. In general, the wave intensity increased with beam current intensity and was stronger when the rocket was charged higher. In DC beam emission, the wave spectrum was broad and decreased with frequency. When the beam was modulated, waves of harmonic structure were generated.

\section{CONCLUSION}

In the international collaboration program between Japan and US on tethered rocket systems, insights have been gained into the behavior of the tether rocket system and its interaction with the ionospheric plasma, with and without electron beam emission. Further data analysis is now in progress. It will offer data which are useful for future large-scale tether experiments in space.

Acknowledgement. We would like to express our sincere thanks to Mr. W. Frank Lau, project manager, for supporting the integration and launch of the Charge-2 rocket.

\section{REFERENCES}

1. W.P. Baker, J.A. Dunkin, Z.J. Galaboff, K.D. Johnston, R.R. Kissel, M.H. Rheinfurth, and M.P.L. Siebel, Tethered Subsatellite Study, NASA TMX-73314, Marshall Space Flight Center (1976).

2. P.M. Banks, P.R. Williamson, and K.I. Oyama, Shuttle Orbiter Tethered Subsatellite for Exploring and Tapping Space Plasmas, Astronautics \& Aeronautics, 31-33 (1981).

3. K. Hirao, N. Kawashima, K.I. Oyama, S. Sasaki, W.J. Raitt, P.M. Banks, and P.R. Williamson, Results of UA-Japan Tethered Payload Experiments, in: Proc. of 14th International Symp. on Space Technol. Science, 1493 (1984).

4. W.J. Raitt, P.R. Williamson, P.M. Banks, N.B. Myers, and N. Kawashima, High Time Resolution Measurements of Rocket Potential Changes Induced by Electron Beam Emission, in: Proc. 14th International Symp. on Space Technol. Science (ISTS), 1501 (1984).

5. S. Sasaki, W.J. Raitt, K.I. Oyama, N. Kawashima, P.R. Williamson, W.F. Sharp, A.B. White, P.M. Banks, T. Yokota, Y. Watanabe, K. Hirao, and T. Obayashi, Results from the series of Tethered Rocket Experiments, submitted to AIAA Journal of Spacecraft and Rockets (1985) 